\title{
Assessing the readiness of small cities in Ghana to tackle overweight and obesity
}

\author{
Noora-Lisa Aberman ${ }^{1}$ (D) Nick Nisbett $^{2} \cdot$ Adjoa Amoafo $^{3} \cdot$ Richmond Areetey $^{4}$
}

Received: 11 February 2021 / Accepted: 17 October 2021 / Published online: 1 January 2022

(c) The Author(s) 2021

\begin{abstract}
The rapid rise in the prevalence of overweight and obesity, and the associated health problems, is an emerging challenge in Ghana, and for women in particular. This study contributes to the understanding of this emerging phenomenon in Ghana by analyzing it from a community perspective, applying the Community Readiness Model in two small cities in Ghana. A series of Key Informant Interviews were undertaken and analyzed, using the model's scoring structure and supplementary textual analysis. We find that communities are aware of overweight and obesity as a health issue, but that it is not prioritized or championed. Furthermore, the diet counseling and keep-fit programs put the responsibility on individuals to address, rather than considering the upstream and structural causes and solutions.
\end{abstract}

Keywords Nutrition transition $\cdot$ Overweight $\cdot$ Urban nutrition $\cdot$ Ghana $\cdot$ Community readiness model (CRM)

\section{Introduction}

Overweight and obesity are associated risk factors for noncommunicable disease (NCDs) such as hypertension, diabetes and some cancers (Ofori-asenso et al., 2016; Steyn \& Mchiza, 2014). The rapid rise in the prevalence of overweight and

This article belongs to the Topical Collection on Stories of Change in Nutrition: Lesson from Africa and Asia

Guest Editors: Stuart Gillespie, Nicholas Nisbett, Mara van de Bold, Jody Harris

Noora-Lisa Aberman

naberman@gainhealth.org

Nick Nisbett

N.Nisbett@ids.ac.uk

Adjoa Amoafo

adjoaamoafo22@gmail.com

Richmond Areetey

raryeetey@ug.edu.gh

1 Global Alliance for Improved Nutrition, Washington, DC, USA

2 Senior Research Fellow, Institute of Development Studies, Brighton, UK

3 Independent Consultant, Accra, Ghana

4 Associate Professor, School of Public Health, University of Ghana, Accra, Ghana obesity, and associated health problems, are seen as an emerging challenge in Ghana, commonly attributed to globalization, urbanization, and the nutrition transition (Abrahams et al., 2011; Rousham et al., 2020). The burden of overweight falls particularly on women: prevalence of overweight and obesity increased from $25 \%$ in 2003 to $40 \%$ in 2014 among women of reproductive age in Ghana (Ghana Statistical Service, 2015). Additionally, $45 \%$ of the burden falls on urban populations.

This study contributes to the understanding of this emerging problem in Ghana based on an understanding of the importance of community health and nutrition behaviors. For instance, ecological approaches to health promotion emphasize the interdependence between an individual's health and lifestyle and surrounding factors such as the community, cultural, physical and social environment (Green et al., 1996). Kesten et al. (2013) suggest that efforts to address obesity among girls should incorporate the community-including families, schools, and the environment-into interventions in order to influence behaviors.

Furthermore, in Ghana people face a number of other competing nutrition and health challenges such as malaria, HIV/ AIDS, diarrheal diseases, and stunting in children. And some studies have demonstrated an acceptance of overweight - though not extreme overweight - for women in Ghana (Aryeetey, 2016; Tuoyire et al., 2018), and Africa more broadly (Pradeilles et al., 2021). Furthermore, gendered barriers to maintaining a healthy weight include time and cultural barriers to physical activity and cultural norms related to women's weight especially before 
and after childbirth (De-Graft Aikins, 2011; Elvis et al., 2018). Thus the extent to which communities consider overweight and obesity to be a priority among competing challenges will have implications for community mobilization and selecting an appropriate strategy (Foster-Fishman et al., 2007; Sliwa et al., 2011). For example, Sliwa et al. (2011) discuss the promise of multi-pronged community-based approaches to childhood obesity prevention when local communities are active and engaged, and they assess community readiness for mobilization as part of their criteria for determining what type of intervention is appropriate.

However, a focus on such community and individual initiatives need to be balanced against the critique coming from health equity literature, which views a focus solely on influencing individual behaviors as a distraction from much stronger, structural drivers of obesity, such as gaps in wider public policy (Friel \& Ford, 2015; Marmot et al., 2008) and the potential adverse effects of a range of 'commercial determinants' (Moodie et al., 2013, pp. 670-679). The literature on the "lifestyle drift" conceptualizes health problems of the individual as downstream issues, while the unescapable structural are much further upstream (Powell et al., 2017; Walls et al., 2018; Williams \& Fullagar, 2019). While active and knowledgeable community leadership is important, this literature suggests that support from further upstream is critical to address - rather than reinforce-health inequalities.

Backholer and colleagues present a useful framework for evaluating the likelihood that an obesity intervention will increase socioeconomic disparities in prevalence (2014). Central to their analysis is the distinction between agentic interventions, which require individuals to make a choice to change behaviors (e.g., nutrition education), and structural "upstream" interventions that alter the environment such that the set of choices is healthier (e.g., ban on unhealthy foods at schools) in a particular context. Additionally, a distinction is made between microenvironmental (home, school, clinic) and macroenvironmental (community, region, nation), such that interventions can be according to level and approach (Backholer et al., 2014).

As such, this study explores the community perspectives and efforts related to overweight and obesity among women in two small cities in Ghana-Techiman and Hohoe. In addition to documenting these community perspectives, we consider the implications for health equity, the gaps in upstream actions, and the extent to which our methodological approach may reinforce some problematic discourses. We apply the Community Readiness Model (CRM), which was developed to assess community readiness to take on an issue (Plested et al., 2006). Based on the model of transtheoretical change which posits that-like individual behavior change-community change moves through various stages of readiness, CRM entails a protocol for measuring community readiness, sometimes referred to as the Community Readiness Tool (Prochaska \& Velicer, 1997).
While this manuscript does not address feminist critiques of obesity literature (see, for instance, Warin, 2015), we situate discussions of overweight and obesity within the literature on gendered norms and preferences related to body size ideals in sub-Saharan Africa.

\section{Methodology}

The Community Readiness Model (CRM) provides a framework for assessing the level of readiness- that is, the degree to which a community is prepared to take action-in order to develop stage-appropriate strategies for addressing the overweight and obesity, while integrating an understanding of the community's culture and resources (Plested, 2006; Stanley, 2014, pp. 2-3). The approach entails structured interviews, with key informants in the community, that correspond to six dimensions of readiness (Stanley, 2014). The model provides an anchored scale by which open-ended responses are scored and averaged across interviews.

The CRM has been utilized largely in high-income countries to assess community readiness of a number of different issues in public health, including obesity (Kesten et al., 2013; Kostadinov et al., 2015). Some CRM studies have also been undertaken in Low and Middle Income Countries (LMICs), examining childhood diarrhea in Mali (Borresen et al., 2016), healthy diets among adolescents girls and women Ghana (Pradeilles et al., 2019), and adolescent obesity in South Africa (Pradeilles et al., 2016).

A number of methodological strengths and weaknesses have been documented in the literature. CRM has been highly praised for its focus on capturing the community perspective and facilitating community-tailored intervention strategies (Kostadinov et al., 2015; Plested et al., 2007; Pradeilles et al., 2016). Kesten et al., (2015, p. 6) emphasize that a community's perception of its situation may be "more important than an objective understanding of what is happening". Kesten et al. (2015) warn that key informants may have a different (higher) level of awareness and readiness than the rest of the community. Many authors raise concerns about quantification of qualitative data, and thus advise triangulation with qualitative analysis, such as textual analysis, in combination with the scoring, to deepen and contextualize the scores (Marks et al., 2019; Plested et al., 2007; Pradeilles et al., 2019), or applying concepts such as theoretical saturation to enhance methodological rigor (Kesten et al., 2015).

\section{Sampling and data collection}

Both municipalities selected for this study are small but quickly urbanizing administrative capitals of their respective districts: Hohoe is in the Volta Region and less than 
$80 \mathrm{~km}$ from Ho, the region's largest urban center; Techiman is one of two main market centers in Bono East Region and is located at a trading crossroads. These study sites were chosen in order to capture the experiences of communities that are in earlier stages of the nutrition transition currently underway in Ghana but are quickly growing and urbanizing. According to national statistics, the prevalence of overweight and obesity among women is 30 percent in Hohoe and 34 percent in Techiman, which is below the national average but still quite high (Ghana Statistical Service, 2015).

The interviews were conducted in February-March 2020. Twenty-six key informants were interviewed (eleven female and fifteen male): 13 in Hohoe and 13 in Techiman. These key informants were representatives from the health sector (including district directors, municipal nutrition officer, and health promotion officer) and education sector (school health education program), religious leaders, the members of the municipal assembly, non-profit organizations (those working in health or nutrition), and private sector representatives (specifically, gym owners). The list of key informants was compiled based on previous research in Ghana (Pradeilles et al., 2019), discussions with municipality nutrition officers, and interviews with women in the communities. Municipality nutrition officers helped identify individuals to interview across the categories. Although overweight and obesity is a gendered problem, our sampling was guided by role rather than gender of the respondent.

A set of 36 structured questions corresponding to six dimensions of readiness (community efforts, community knowledge of efforts, leadership, community climate, knowledge of the issue, and resources for prevention efforts) were asked to the key informants. The CRM interview guide (from Stanley, 2014, as presented in University of Kansas, n.d.) was adapted based on three pilot interviews with health-sector representatives in Hohoe, whose responses were not included in the analysis. Adaptations included context-relevant prompts and terminology for questions that were not clear to pilot respondents, but all the original questions were retained. Interviews were conducted in the language preferred by the interviewee: either English, Ewe, or Twi. The interviews were conducted by a researcher, fluent in Engplish and Twi, and a research assistant who acted as translator when Ewe was used. In each community, a representative from the Health Directorate served as the community liaison.

\section{Analysis}

Responses from key informants were transcribed verbatim and translated to English, when necessary. After an initial read to become familiar with the transcripts, interviews were scored by two researchers independently, and then scores were compared and discussed, especially in the case of different scores. This process requires researchers to be explicit about their interpretations of the data and anchor statements, which supports clarity, consistency, and minimizes bias. The final scores represent a consensus (not average) score by the two researchers after discussion and agreement of the rationale for the score.

Responses for each of the six dimensions are scored (scale of 1-9) on the level of readiness: Statements made by each key informant is matched to descriptive (anchor) statements on a Likert scale (adapted from Stanley, 2014, p. 13), corresponding to a level of readiness on a scale of 1-9; from 1 (no awareness) to 9 (high level of community ownership), as depicted in Fig. 1. The score for each dimension is the mean of all respondents' scores, and the overall readiness score for each location is derived by averaging the six dimension scores. If a community has exceeded one level but has not fully attained the next level, a score is given in between the two levels (Stanley, 2014).

The scoring criteria were revised as needed to fit the local context. For instance, the two scorers agreed to include small-scale informal activities like keep-fit clubs and private sector efforts like gymnasia as "community efforts" to address the overweight and obesity because of their perceived importance.

After scoring, numeric results are triangulated with qualitative analysis-interview transcripts were coded using a combination of Nvivo qualitative analysis software and Excel for developing framework matrices by community. The six dimensions of readiness served as a priori themes, while sub-themes (13) and codes (2-4 per sub-theme) were based on emergent patterns during the coding process. Illustrative quotes are provided for a subset of particularly salient sub-themes within each dimension of readiness, and qualitative results (patterns of responses across interviews and locations) are described in the text to assist in interpretation of the readiness scores. Although themes and sub-themes were consistent across locations, they were coded separately and considered jointly in the final stage of analysis. Ethical approval was received from the Ghana Health Service Ethical Review Committee (GHS-ERC) prior to the start of data collection. Recordings and transcripts are kept in a password protected folder and all quotes presented have been anonymized.

\section{Community Readiness Results}

Twenty-six (26) key informants were interviewed from the Hohoe and Techiman Municipality. Eight (61.5\%) were males and $5(38.5 \%)$ were females in Hohoe, while $7(53.8 \%)$ males and $6(46.2 \%)$ females were from Techiman. A large proportion of the key informants were from 
Fig. 1 CRM Stages of Readiness

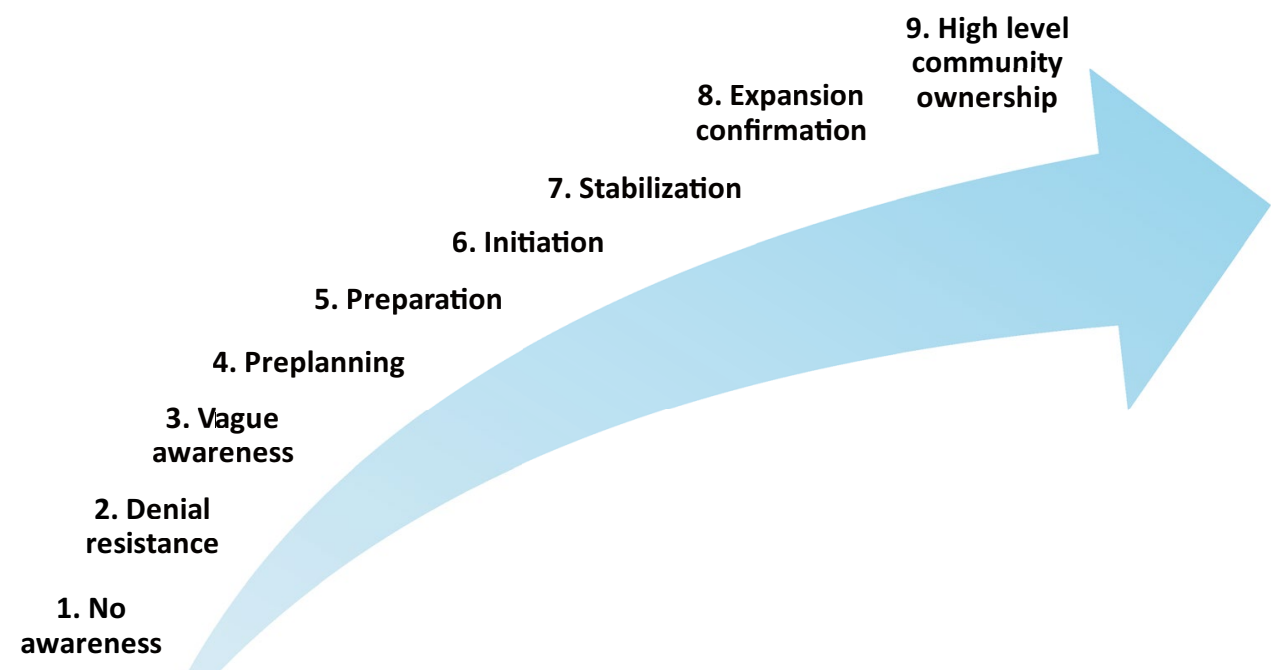

the health sector-6 $(46.1 \%)$ and $5(38.5 \%)$ from Hohoe and Techiman, respectively. In both cities, there were 3 $(23.1 \%)$ key informants from the religious institutions, while the rest were from the public sector (Table 1).

The results of the analysis are presented here, organized by the CRM dimensions of readiness. The rationale for the score and supportive quotes are presented by city to enhance understanding of the situation and help suggest next steps for the communities to enhance readiness to prevent and address overweight and obesity among women.

Table 1 Characteristics of key informants

\begin{tabular}{|c|c|c|c|c|c|}
\hline & & \multicolumn{2}{|c|}{$\begin{array}{l}\text { Hohoe } \\
\text { Municipality } \\
(n=13)\end{array}$} & \multicolumn{2}{|c|}{$\begin{array}{l}\text { Techiman } \\
\text { Municipality } \\
(\mathrm{n}=13)\end{array}$} \\
\hline & & $\mathrm{n}$ & $\%$ & $\mathrm{n}$ & $\%$ \\
\hline \multirow[t]{2}{*}{ Sex } & Male & 8 & 61.5 & 7 & 53.8 \\
\hline & Female & 5 & 38.5 & 6 & 46.2 \\
\hline \multirow{6}{*}{$\begin{array}{l}\text { Sectors/ } \\
\text { roles of key } \\
\text { informants }\end{array}$} & $\begin{array}{l}\text { Non-Governmental } \\
\text { Organization }\end{array}$ & 1 & 7.1 & 1 & 7.7 \\
\hline & Health $^{\text {a }}$ & 6 & 46.1 & 5 & 38.5 \\
\hline & Religious Leaders ${ }^{b}$ & 3 & 23.1 & 3 & 23.1 \\
\hline & Gym owner & 1 & 7.7 & 1 & 7.7 \\
\hline & Education $^{c}$ & 1 & 7.7 & 1 & 7.7 \\
\hline & $\begin{array}{l}\text { District Assembly } \\
\text { Member }\end{array}$ & 1 & 7.7 & 2 & 15.4 \\
\hline
\end{tabular}

a Health sector included Nutrition Officers, Directors of Ghana Health Services, Head Nurses and Health Promotion Officer

${ }^{b}$ Religious leaders included pastors from various Christian sects as well as imams

${ }^{\mathrm{c}}$ Education included School Health Education Program Officers
The outcome of the CRM analysis indicates that Hohoe has an overall readiness score of 3.18, which corresponds to "vague awareness", shown in Table 1. In Techiman, the overall score was 2.43 , corresponding to the denial or resistance stage. The vague awareness stage is described in the model as a situation wherein "most feel that there is a local concern, but there is no immediate motivation to do anything about it". The denial/resistance stage is described as a situation wherein "At least some community members recognize that it is a concern, but there is little recognition that it might be occurring locally".

Dimension A considers the existing community efforts-including programs, activities and policies-to prevent and address overweight and obesity in women. Hohoe and Techiman scored similarly for this dimension (efforts in place to address overweight and obesity among women). Hohoe had a score of $3.85 \pm 0.52$ while Techiman scored $3.38 \pm 0.96$ (Table 2). The score indicates that both communities have achieved stage 3-vague awareness - but have not fully attained stage 4 , preplanning. Some community members recognize a need to initiate some type of effort, but the efforts in place were mostly small-scale, uncoordinated, and with broader social and health objectives rather than explicit objectives related to overweight and obesity.

In both cities, localized efforts were common (see illustrative quotes in Table 3.1). Commonly organized by religious institutions were "keep-fit" clubs_-wherein members would meet to walk or exercise on a weekly basis - and health education talks. Private gyms were available for a membership fee, although. Herbalists or vendors commonly offered tonics for decreasing (or increasing) body size. Formal healthsector initiatives included general public health education meetings (Table 3.2). Dissemination of health messages 
Table 2 Community readiness scores

\begin{tabular}{|c|c|c|c|c|c|c|c|}
\hline & \multirow[t]{2}{*}{ Overall Readiness } & \multicolumn{6}{|l|}{ Dimensions } \\
\hline & & $\begin{array}{l}\text { Community } \\
\text { efforts }\end{array}$ & $\begin{array}{l}\text { Knowledge } \\
\text { of efforts }\end{array}$ & Leadership & Community climate & Knowledge of issue & Resources \\
\hline $\begin{array}{l}\text { Hohoe } \\
\text { Mean } \\
\text { scores } \\
\text { (SD) }\end{array}$ & 3.18 (0.46) Vague Awareness & $3.85(0.52)$ & $3.58(0.66)$ & $3.15(0.97)$ & $2.65(1.11)$ & $2.87(0.80)$ & $2.96(0.80)$ \\
\hline $\begin{array}{l}\text { Techiman } \\
\text { Mean } \\
\text { scores } \\
\text { (SD) }\end{array}$ & 2.43 (0.79) Denial/ Resistance & $3.38(0.96)$ & $2.48(0.81)$ & $2.04(0.74)$ & $2.12(1.21)$ & $2.54(1.03)$ & $2.00(0.00)$ \\
\hline
\end{tabular}

$\mathrm{SD}=$ Standard deviation

Source: Authors' calculations from study data

by radio, sometimes, covered issues related to overweight and obesity. In addition, occasional public weight screenings were meant to raise awareness about overweight and obesity, while clinical care for non-communicable diseases was commonly referred to as treatment for overweight- and obesity-related outcomes.

The most developed efforts are those addressing NCDs. Health sector respondents noted that they meet with people at risk of or suffering from NCDs in small groups where people are able to ask questions and better understand the issues and what actions they can take personally. The public health education meetings were able to reach a larger number of people, creating awareness about various health issuesoverweight and obesity often among them. One respondent in Hohoe noted that the keep-fit clubs allowed people with no exposure to practicing exercise to appreciate its benefits. Similarly, a gym owner in Techiman emphasized that gyms allow people the opportunity to reintroduce physical activity into their lives as modern life requires very little activity.

In Hohoe, mobilizing people to attend community health meetings, also called "durbars", was seen as a challenge, exposing weaknesses of this broad approach. Comprehension of the messages around healthy eating and activity (and affordability of prescribed foods) was considered a barrier to adoption, along with a lack of community acceptance of overweight and obesity as a problem (Table 3.3), as discussed in more detail below. Inadequate funding for regular community health activities was seen as a challenge for reach, while insufficient coordination and lack of dedicated funding for overweight and obesity was said to decrease the effectiveness of the efforts in place. In Techiman, a lack of coordination of efforts was also mentioned as an important weakness. Here, respondents also discussed gender norms that make it inappropriate for men and women to interact in, for instance, keep-fit clubs, especially but not exclusively in the Muslim community. Misinformation was also raised in Techiman; it was noted that if people want to increase or decrease their body size they often rely on tonics and herbs and may be influenced by advice from vendors unqualified to give medical advice.

Dimension B considers the extent to which community members know about and understand these efforts. Key informants in Hohoe more commonly felt that there was some awareness of efforts in place, although limited knowledge of the details and purpose, compared to those in Techiman. Community knowledge of effort in Hohoe was scored at $3.58 \pm 0.66$ (Table 2), suggesting that the community has attained and begun to surpass stage 3 , wherein a few community members have heard of some of the efforts, but the extent of their knowledge is limited. Techiman had a lower score of $2.48 \pm 0.81$, which implies the community passed the stage wherein the community has no knowledge about the efforts but has not yet reached stage 3 .

Most informants in Hohoe thought that some community members would have exposure to the efforts in place because health workers regularly visit neighborhoods for community health events, messages may be heard on the radio, and keep-fits are common throughout the community (Table 4). They suggested that if or when community members consider themselves to have a health problem related to overweight or obesity, they would know to go to health workers and hospitals for advice or care. A few respondents noted that the community's awareness of the connection of obesity to NCDs has been increasing.

In Techiman, there was a range of responses, but many respondents were skeptical that community members had sufficient awareness of efforts for tackling overweight and obesity. Discussion of awareness were tied up with the extent to which people think it is an issue that pertains to them, to some extent combining awareness of efforts with community climate. Respondents felt that these were linked because many in the community would not take notice of any efforts because overweight and obesity are not issues they consider important. The affluent and the youth were thought 


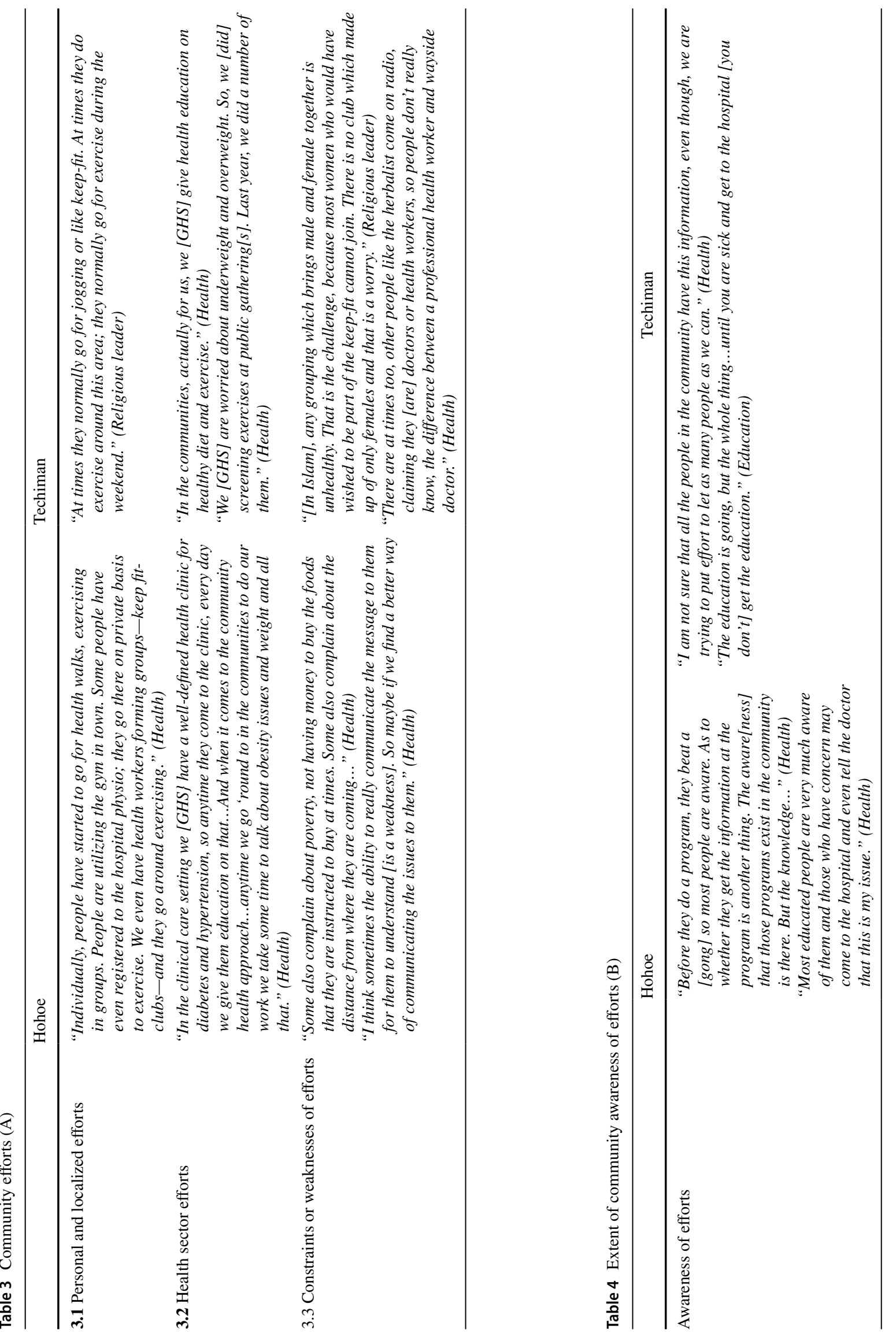


to be more likely to be aware of efforts and concerned with the issue. Awareness of community-level initiatives was described as higher than awareness of the formal healthsector initiatives. One respondent noted that most people are only made aware of formal efforts when they go to the hospital with weight-related health problems. However, some respondents noted that awareness of the connection between body weight and health was increasing in the community.

Dimension C considers leadership-including appointed leaders and influential community members-support for addressing the issue. The leaders listed by respondents in both locations included religious leaders, health and education directorate representatives, politicians, and traditional leaders (Table 5.1).

The score for this dimension in Hohoe was $3.15 \pm 0.97$, corresponding to vague awareness, wherein leadership has started to recognize the need to do something regarding the issue. Techiman on the other hand was at the Denial/Resistance stage with a score of $2.04 \pm 0.74$, wherein most leaders do not recognize the issue as an important one in their community.

In Hohoe, respondents suggested that leaders within the health sector consider obesity to be a concern, but that outside the health sector leadership lacks appreciation of the issue (Table 5.2). Religious leaders said they are championing the issue in their congregations. All respondents felt leadership would support additional efforts. However, it was not clear if they meant leadership would champion the issue versus simply accepting funding from external sources.

In Techiman, respondents thought that most leaders do not consider the issue of overweight to be an important concern, with the exception of frontline health workers. One respondent suggested that there were other, more pressing, priorities (Table 5.3). In spite of this, most respondents felt that leaders would be supportive of additional efforts on the issue if it were communicated and designed appropriately. Respondents in both communities noted the absence of local champions for the issue.

Dimension D considers the community climate or attitude about the issue. This dimension generated the highest variation of responses. The score for the community climate dimension was $2.65 \pm 1.11$ for Hohoe and $2.12 \pm 1.21$ for Techiman (Table 2). A score of 2 denotes the Denial/ Resistance stage, wherein the prevailing attitude is that it (overweight and obesity) is just a part of the culture and/or does not need any attention. Both communities surpassed stage 2, moving towards stage 3-a neutral stance wherein community members feel it is a personal problem or fails to connect body size to correlated health problems.

Overweight and obesity were overwhelmingly described as accepted or desired in both communities, unless it inhibits someone's general movement and functioning (Table 6.1). However, there were also mentions of growing awareness among some people — especially among higher income and younger people — of the risks and challenges related to overnutrition and of changing body ideals (Table 6.2). In Hohoe, a respondent emphasized that his congregation was not concerned with obesity as a problem per se, but that the youth seek to be healthy and fit. In Techiman a religious leader described overweight and obesity as a personal problem rather than a community issue.

Dimension E concerns the extent of the community's knowledge and understanding of the issue. Hohoe scored $2.87 \pm 0.80$ whereas Techiman scored $2.54 \pm 1.03$ (Table 2), indicating that both communities have passed stage

Table 5 Community leadership on the issue (C)

\begin{tabular}{|c|c|c|}
\hline & Hohoe & Techiman \\
\hline $\begin{array}{l}5.1 \\
\text { Key leaders }\end{array}$ & $\begin{array}{l}\text { “...I think those in the hospitals are doing their best-speaking to them, } \\
\text { going to the media houses. And maybe they should do more. And the } \\
\text { churches...they will be in a better position. And also the mosques } \\
\text { led by the Imams as well as the chiefs and queen-mothers. And the } \\
\text { schools, especially the tertiary institutions.” (NGO) }\end{array}$ & $\begin{array}{l}\text { "The assembly members, political heads, } \\
\text { they can easily transmit that information } \\
\text { to the community because they handle the } \\
\text { problems in the community. Any problem of } \\
\text { the community is forwarded to the assembly } \\
\text { members." (Municipal government) }\end{array}$ \\
\hline $\begin{array}{l}5.2 \\
\text { Leadership extent } \\
\text { of concern and } \\
\text { commitment }\end{array}$ & $\begin{array}{l}\text { "It's of a great concern because we are never happy to hear that a } \\
\text { brother of us is ill, we are not happy to hear that our brother died } \\
\text { unexpectedly, it's a big problem and of much concern and we don't } \\
\text { know what to even do." (Religious leader) }\end{array}$ & $\begin{array}{l}\text { “...those who are much concern[ed], it is just } \\
\text { a handful, but the majority are not bothered." } \\
\text { (Health) } \\
\text { "We don't have leadership, who have taken } \\
\text { upon themselves to work on overweight and } \\
\text { obesity in this community" (Religious leader) }\end{array}$ \\
\hline $\begin{array}{l}\text { 5.3Competing } \\
\text { priorities }\end{array}$ & $\begin{array}{l}\text { “...right now... sanitation has become a problem. Because now you } \\
\text { can see that it is not raining, so the water that the women have been } \\
\text { throwing away and the [malarial] mosquitos are more dangerous than } \\
\text { the questions you are asking me [about obesity].” (Religious leader) }\end{array}$ & \\
\hline
\end{tabular}


Table 6 Community climate on the issue (D)

\begin{tabular}{|c|c|c|}
\hline & Hohoe & Techiman \\
\hline $\begin{array}{l}\text { 6.1 Community extent of } \\
\text { concern }\end{array}$ & $\begin{array}{l}\text { "Sometimes when they come to you that may not be the main the } \\
\text { issue like some of the diabetic or hypertensive after weighing, } \\
\text { checking; 'oh madam you are obese' and they would say 'oh } \\
\text { (I) am ok, my family we've all been fat', ah ha. So at that point } \\
\text { you see that they have accepted it to be a norm in the family } \\
\text { which it isn't. which is even having a rippling effect on their } \\
\text { health so hmm, it's true that they are trying to tolerate it which } \\
\text { it shouldn't be" (Health) }\end{array}$ & $\begin{array}{l}\text { "Here we cherish it...this lady has enough body } \\
\text { and she is looking nice and beautiful. We are } \\
\text { happy and appreciate people who are big. } \\
\text { (Education) } \\
\text { "But the overweight and obesity, we don't see } \\
\text { anything about that. You hardly hear someone } \\
\text { dead as a result of obesity, so why should we } \\
\text { be worried?" (Municipal government) }\end{array}$ \\
\hline $\begin{array}{l}\text { 6.2Growing community } \\
\text { awareness }\end{array}$ & $\begin{array}{l}\text { "Young people today per my own observations, want to live and } \\
\text { have a body stature of fitness and slim stature." (Religious } \\
\text { leader) } \\
\text { "Among community members, people are more concerned about } \\
\text { obesity because of the frequent education and health talks, } \\
\text { people call [into the radio] and ask questions; they phone in." } \\
\text { (Health) }\end{array}$ & $\begin{array}{l}\text { "For the past times, people, actually, cherish fat } \\
\text { people, but now people are getting information } \\
\text { that fatness has a lot of problems. I don't think } \\
\text { now people cherish fatness." (Health) } \\
\text { "Somehow, a few [in the] working class are } \\
\text { beginning to think that it is a problem. So } \\
\text { they themselves maybe online do some checks } \\
\text { to change their lifestyle and other things." } \\
\text { (Health) }\end{array}$ \\
\hline
\end{tabular}

2-denial and resistance wherein there is no knowledge that overweight and obesity are impacting the communitytowards stage 3 wherein have some knowledge about the issue and how to avoid it but do not prioritize it or appreciate the associated health risks.

This dimension underlines the gap between awareness raising and knowledge and understanding. In Hohoe, respondents repeatedly suggested that some information is being disseminated, but that it is not sufficient to support deeper understanding of the e health risks associated with obesity or counteract the current community climate (Table 7.1). However, some pointed to wide participation in keep-fit clubs and commonly prescribed diet guidance, such as the view that it is best to eat light food in the evening, as evidence that people are increasingly seeing healthy body weight as a part of healthy living (Table 7.3). Although they also note that people fund it difficult to follow this advice due to modern schedules and lifestyles.

Many respondents in Techiman discussed gaps in knowledge of the burden of overweight and obesity in the community, while others focused on the limited understanding the health risks associated with overweight and obesity that would have them prioritize the issue (Table 7.2).

In both communities, it was suggested that the wealthy more commonly understand causes and risks associated with the issue. Furthermore, the incidence of overweight and obesity are not tracked by the health systems in either community so there are no formal statistics on the prevalence with which to sensitize community members to the extent of the problem.

Dimension F considers the human and financial resources available for prevention and mitigation. The last dimension also scored $2.96 \pm 0.80$ for Hohoe and $2.00 \pm 0.00$ for Techiman (Table 2), indicating that Techiman is squarely in the denial resistance stage wherein communities have no dedicated funding or capacity allocated to address the issue. Whereas Hohoe has attained stage 2 and is close to attaining stage 3 , wherein the community is not sure how to garner resources to address the issue.

In Hohoe, most respondents agreed that there was expertise on the issue in the health sector, although some noted that only nutritionists (not nurses or other frontline healthcare workers) were trained on this issue (Table 8.1). They also specified that the expertise was in the health sector, not among others in the community. Some respondents noted that people tend to avoid formal healthcare unless faced with an acute illness and thus would not be likely to access this expertise until they had a problem (Table 8.2).

In Techiman, a few respondents considered healthcare workers to have sufficient expertise. Others felt that training was lacking on the issue, even among nutritionists. Similar to Hohoe, they lamented the tendency to seek advice on body size and overall health from herbalists and other informal health sector actors who lack formal training.

In both locations, localized efforts were often funded through church budgets or individual contributions (Table 8.3). There was no dedicated funding for formal health sector efforts; it was noted that any activities to address overweight and obesity were undertaken as a part of regular "day to day activities".

\section{Discussion}

The CRM analysis illuminates the extent of community readiness to take on the rising problem of overweight and obesity in two small but quickly growing cities in Ghana. 
While similar studies have been undertaken in major urban centers in Ghana, these study sites provide a glimpse at the evolving nutrition transition and as well as an opportunity to consider support to healthy diets and lifestyles rather than dealing with the effects of their absence.

Across both communities, localized efforts such as keepfit clubs and health talks were commonly implemented to promote health and well-being. While not always explicitly focused on overweight and obesity, these initiatives were both affordable and integrated into existing social and cultural activities, often organized by religious groups-religion being central to social life in Ghana. Local community leaders, especially religious leaders, were central to these efforts and so their awareness of the issue was critical. A study in South Africa found that religious leaders are role models and can indeed play an important role in supporting healthy behaviours (Pradeilles et al., 2016).

While concern about overweight and obesity - in contrast to traditional ideals supporting a larger body size for women - was described by respondents, this was primarily framed in terms of changing body ideals along younger and higher income residents, rather than greater awareness of body size as connected to overall health. Similarly, a CRM study in urban Ghana by Pradeilles et al. found a limited knowledge of the connection between "unhealthy" diets and lifestyles and specific health consequences (2019). A thin body stature was described as primarily desirable among the young. A related systematic review similarly reports that acculturative stress to look slimmer was only reported by younger women and adolescents (Pradeilles et al., 2021).

Health sector leaders were unaware of any upstream policy directives or strategies to guide their activities to address overweight and obesity and dedicated funding was nonexistent, according to these respondents. As such, the burden of addressing the emerging issue fell to local leaders, sharing funding from existing activities. Many local leaders considered the problem to lie with the communities-blaming the Ghanaian tradition of appreciating larger body sizes as a sign of prosperity, or otherwise pushing the responsibility for change on to individual community members. However, healthcare workers largely felt that support to communities was inadequate, and that more funding for education and behavior change communication was required. And the bulk of formal health sector activities focused on treatment - such as for NCDs - rather than prevention.

Eating late at night due to a busy schedule was also considered to be a cause of overweight and obesity. In contrast, study respondents in the more urbanized setting of Accra perceived "fast food" and takeout food to be the more important dietary causes of overweight (Pradeilles et al., 2019). Similar to Tuakli-Wosornu et al., 2014 


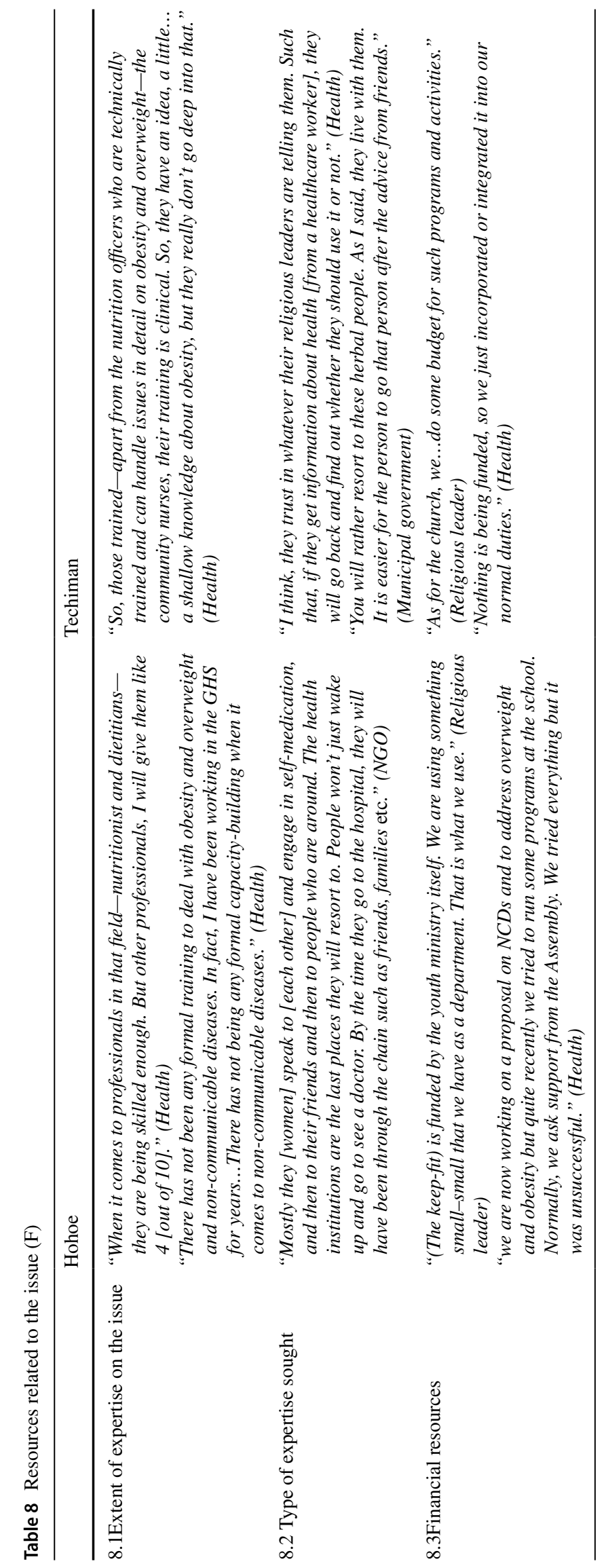


participants perceived rigorous physical activity such as gym participation as unappealing to women (2014). Many local leaders in this study and in previous studies suggest that women aspire to larger body sizes (Aryeetey, 2016; Tuoyire et al., 2018). However, there was little to no recognition among leaders of the gendered pressures and norms that underlie diet and activity preferences among women: De-Graft Aikins describs the pressures women feel, especially by older female relatives, to limit physical activity and eat highly caloric, cultural prescribed foods during pregnancy and breastfeeding (2011).

Income and time poverty were referred to as drivers of overweight among women. Affordability was suggested to be one barrier to healthy eating - such as the ability to afford plentiful fresh foods. Low-income community members were clearly unable to pay for gym memberships, and they were also described as less likely to seek medical care, where they might be exposed to health education. This highlights the contradiction in local perceptions that weight gain is a sign of prosperity, although the poor and less educated have fewer resources (and potentially less exposure to "western" body ideals) with which to maintain a healthy weight. (Ziraba et al., 2009) analyze trends in overweight and obesity among urban women throughout sub-Saharan Africa and find a higher increase among the urban poor (2009).

Applying a health-equity lens to these results will help identify program and policy options that support more equitable outcomes. The framework for analysis of obesity programs by Backholer et al. (2014) illuminates the extent to which efforts to address obesity in these communities are primarily agentic: requiring individuals to choose to change their behavior rather than considering how the environment can be altered to provide a better set of choices. The bulk of efforts were related to awareness raising, either one-on-one or in neighborhood "durbars" or on local radio programs. While these activities may be part of the solution in order to shift community climate and knowledge on the issue, they are likely insufficient to enable those with fewer resources (poor) and less agency (women) to choose healthier behaviors and diets. Keepfit clubs and other church- or mosque-based activities may be considered agento-structural-in that the decision to take part is embedded in existing activities and lead by religious role model. In terms of scale, some of the efforts are community- or neighborhood-wide, and thus considered macroenvironmental. However, health sector respondents were unaware of any upstream policy directives or strategies to guide their activities to address overweight and obesity and dedicated funding was nonexistent. While Backholer et al. concede that macroenvironmental efforts are not necessarily more equitable or structural, they are theoretically more likely to have broader effect (2014).

\subsection{Conclusions}

The Lancet Commission on the Global Syndemic of Obesity, Undernutrition and Climate Change emphasises the importance of joined up action between local and national levels, with two of the key messages stressing action at this level: "Strengthen municipal governance levers to mobilise action at the local level and Create pressure for national action"; "Strengthen civil society engagement to encourage systemic change and pressure policy action at all levels of government [...]" (Swinburn et al. 2019:2). In this context the CRM has been useful for highlighting that efforts in these two municipalities, and nationally in Ghana, are not yet adequate to the scale of the challenge facing public health. One weakness we highlighted via undertaking the CRM is that efforts are largely agentic and localized. Community leaders, especially religious leaders, are trusted sources of information and some have become champions. But at the same time, community pressure around weight or a lack of physical exercise, when decoupled from an awareness of the broader national picture suggested by the Lancet report; can lead to unnecessary stigma and shame.

The CRM process illuminated important lessons, necessary for supporting health and wellbeing in these two communities. However, considering the results in this broader context, application of this tool on the issue of overweight and obesity calls for a refocus that acknowledges the dependence of a given community on the systems, policies, and funding flows from above. Community climate and resources are the two weakest dimensions for both communities - but in a context where the community's understanding of the role of national policy is unexplored. Raising awareness of healthy living behaviors and training nutritionists to provide better advice are critical for a healthy community and must be combined with an understanding of and strategy for engaging national government.

Supplementary Information The online version contains supplementary material available at https://doi.org/10.1007/s12571-021-01234-z.

Acknowledgements We are grateful to Michelle Holdsworth for her early advice, including the suggestion to use the community readiness model, to Tabitha Hrynick for her thoughtful literature review, and to Victoria Elorm Debge for her excellent field support, and to Irene Devine Dzirasa, Carl Makafui Agbittor, and Leticia Bayor for their indispensable assistance during field planning and data collection. Funding for this work was received by Stories of Challenge/A4NH and the Netherlands 
Development Organisation (SNV), through its Voice for Change Partnership (V4CP) Programme.

\section{Declarations}

Conflict of Interest The authors have no conflicts of interest to declare that are relevant to the content of this article.

Open Access This article is licensed under a Creative Commons Attribution 4.0 International License, which permits use, sharing, adaptation, distribution and reproduction in any medium or format, as long as you give appropriate credit to the original author(s) and the source, provide a link to the Creative Commons licence, and indicate if changes were made. The images or other third party material in this article are included in the article's Creative Commons licence, unless indicated otherwise in a credit line to the material. If material is not included in the article's Creative Commons licence and your intended use is not permitted by statutory regulation or exceeds the permitted use, you will need to obtain permission directly from the copyright holder. To view a copy of this licence, visit http://creativecommons.org/licenses/by/4.0/.

\section{References}

Abrahams, Z., Mchiza, Z., \& Steyn, N. P. (2011). Diet and mortality rates in Sub-Saharan Africa: Stages in the nutrition transition. BMC Public Health 11(1), 1-12. https://doi.org/10.1186/ 1471-2458-11-801

Aryeetey, R. N. O. (2016). Perceptions and Experiences of Overweight among Women in the Ga East District Ghana. Frontiers in Nutrition 3 https://doi.org/10.3389/fnut.2016.00013

Backholer, K., Beauchamp, A., Ball, K., Turrell, G., Martin, J., Woods, J., \& Peeters, A. (2014). A Framework for Evaluating the Impact of Obesity Prevention Strategies on Socioeconomic Inequalities in Weight. American Journal of Public Health, 104(10), 43-51. https://doi.org/10.2105/AJPH.2014.302066

Borresen, E. C., Stone, C., Boré, A., Cissoko, A., Maiga, A., Koita, O. A., \& Ryan, E. P. (2016). Assessing community readiness to reduce childhood diarrheal disease and improve food security in Dioro, Mali. International Journal of Environmental Research and Public Health, 13(6). https://pubmed.ncbi.nlm.nih.gov/ 27338428/

De-Graft Aikins, A. (2011). Culture, Diet and the Maternal Body: Ghanaian Women's Perspectives on Food, Fat and Childbearing. In M. Unnithan-Kumar \& S. Tremayne (Eds.), Fatness and the maternal body: women's experiences of corporeality and the shaping of social policy. Berghahn Books.

Elvis, J. H., Asamoah, N., Hormenu, T., Pollmann, D., \& Schack, T. (2018). Managing Overweight and Obesity in Ghana from a Cultural Lens: The Complementary Role of Behaviour Modification. JOURNAL OF PREVENTIVE MEDICINE AND CARE, 24743585. https://doi.org/10.14302/issn.2474-3585.jpmc-18-2059

Foster-Fishman, P. G., Cantillon, D., Pierce, S. J., \& Van Egeren, L. A. (2007). Building an active citizenry: The role of neighborhood problems, readiness, and capacity for change. American Journal of Community Psychology, 39(1-2), 91-106. https://doi.org/10. 1007/s10464-007-9097-0

Friel, S., \& Ford, L. (2015). Systems, food security and human health. Food Security, 7(2), 437-451. https://doi.org/10.1007/ s12571-015-0433-1

Ghana Statistical Service. (2015). Ghana Demographic Health Survey. Ghana Statistical Service, 530.

Green, L. W., Richard, L., \& Potvin, L. (1996). Ecological Foundations of Health Promotion. American Journal of Health Promotion, March. https://doi.org/10.4278/0890-1171-10.4.270
Kesten, J. M., Cameron, N., \& Griffiths, P. L. (2013). Assessing community readiness for overweight and obesity prevention in preadolescent girls : A case study. BMC Public Health, 13, 1205.

Kesten, J. M., Griffiths, P. L., \& Cameron, N. (2015). A critical discussion of the Community Readiness Model using a case study of childhood obesity prevention in England. Health and Social Care in the Community, 23(3), 262-271. https://doi.org/10.1111/hsc.12139

Kostadinov, I., Daniel, M., Stanley, L., Gancia, A., \& Cargo, M. (2015). A Systematic Review of Community Readiness Tool Applications : Implications for Reporting. International Journal of Environmental Research and Public Health, 12, 3453-3468. https:// doi.org/10.3390/ijerph120403453

Marks, J., Barnett, L. M., \& Allender, S. (2019). Is school community perception of student weight status a barrier for addressing childhood obesity? Health Promotion Journal of Australia, 30, 28-36. https://doi.org/10.1002/hpja.172

Marmot, M., Friel, S., Bell, R., Houweling, T. A., \& Taylor, S. (2008). Closing the gap in a generation: Health equity through action on the social determinants of health. The Lancet, 372(9650), 16611669. https://doi.org/10.1016/S0140-6736(08)61690-6

Moodie, R., Stuckler, D., Monteiro, C., Sheron, N., Neal, B., Thamarangsi, T., Lincoln, P., \& Casswell, S. (2013). Profits and pandemics: Prevention of harmful effects of tobacco, alcohol, and ultra-processed food and drink industries. The Lancet, 381(9867), 670-679. https://doi. org/10.1016/S0140-6736(12)62089-3

Ofori-asenso, R., Agyeman, A. A., Laar, A., \& Boateng, D. (2016). Overweight and obesity epidemic in Ghana - a systematic review and meta-analysis. BMC Public Health. https://doi.org/10.1186/ s12889-016-3901-4

Plested, B. A., Edwards, R. W., \& Jumper-Thurman, P. (2006). Community Readiness: A Handbook for Successful Change.

Plested, B. A., Edwards, R. W., \& Thurman, P. J. (2007). Disparities in Community Readiness for HIV / AIDS prevention Disparities in Community Readiness for HIV / AIDS Prevention. Substance Use \& Misuse, 42, 729-739. https://doi.org/10.1080/ 10826080701202551

Powell, K., Thurston, M., \& Bloyce, D. (2017). Theorising lifestyle drift in health promotion: explaining community and voluntary sector engagement practices in disadvantaged areas. Critical Public Health, 1-12.

Pradeilles, R., Holdsworth, M., Olaitan, O., Irache, A., Osei-Kwasi, H. A., Ngandu, C. B., Cohen, E. (2021). Body size preferences for women and adolescent girls living in Africa: A mixed-methods systematic review. Public Health Nutrition, 1-22.https://doi.org/ 10.1017/S1368980021000768

Pradeilles, R., Marr, C., Laar, A., Holdsworth, M., Zotor, F., Tandoh, A., Klomegah, S., Coleman, N., Bash, K., Green, M., \& Griffiths, P. L. (2019). How ready are communities to implement actions to improve diets of adolescent girls and women in urban Ghana ? 1-14.

Pradeilles, R., Rousham, E. K., Norris, S. A., Kesten, J. M., \& Griffiths, P. L. (2016). Community readiness for adolescents' overweight and obesity prevention is low in urban South Africa : a case study. 1-12. https://doi.org/10.1186/s12889-016-3451-9

Prochaska, J. O., \& Velicer, W. F. (1997). The Transtheoretical Change Model of Health Behavior. American Journal of Health Promotion, 12(1), 38-48.

Rousham, E. K., Pradeilles, R., Akparibo, R., Aryeetey, R., Bash, K., Booth, A., Muthuri, S. K., Osei-Kwasi, H., Marr, C. M., Norris, T., \& Holdsworth, M. (2020). Dietary behaviours in the context of nutrition transition: A systematic review and meta-analyses in two African countries. Public Health Nutrition, 23(11), 1948-1964. https://doi.org/10.1017/S1368980019004014

Sliwa, S., Goldgerg, J. P., Clark, V., Collins, J., Edwards, R., Hyatt, R. R., Junot, B., Nahar, E., Nelson, M., Tovar, A., \& Economos, C. D. (2011). Using the Community Readiness Model to Select Communities for a Community-Wide Obesity Prevention Intervention. Preventing Chronic Disease, 8(6), A150. 
Stanley, L. R. (2014). Community Readiness Assessment Guidance (Adapted from the Tri-Ethnic Center Community Readiness Handbook, 2nd edition). https://ctb.ku.edu/en/table-of-contents/overview/models-forcommunity-health-and-development/community-readiness/main

Steyn, N. P., \& Mchiza, Z. J. (2014). Obesity and the Nutrition Transition in Sub-Saharan Africa., 1311, 88-101. https://doi.org/10. 1111/nyas. 12433

Swinburn, B. A., Kraak, V. I., Allender, S., Atkins, V. J., Baker, P. I., Bogard, J. R., Brinsden, H., Calvillo, A., Schutter, O. De, Devarajan, R., Ezzati, M., Friel, S., Goenka, S., Hammond, R. A., Hastings, G., Hawkes, C., Herrero, M., Hovmand, P. S., Howden, M., Dietz, W. H. (2019). The Global Syndemic of Obesity, Undernutrition, and Climate Change: The Lancet Commission report. The Lancet, 393(10173), 791-846. https://doi.org/10.1016/S0140-6736(18)32822-8

Tuakli-Wosornu, Y. A., Rowan, M., \& Gittelsohn, J. (2014). Perceptions of physical activity, activity preferences and health among a group of adult women in urban Ghana: A pilot study. Ghana Medical Journal, 48(1), 3-13. https://doi.org/10.4314/gmj.v48i1.1

Tuoyire, D. A., Kumi-Kyereme, A., Doku, D. T., \& Amo-Adjei, J. (2018). Perceived ideal body size of Ghanaian women: "Not too skinny, but not too fat." Women and Health, 58(5), 583-597. https://doi.org/10.1080/03630242.2017.1321607

University of Kansas. (n.d.). Community Readiness. Community Tool Box. Retrieved August 17, 2021, from https://ctb.ku.edu/ en/table-of-contents/overview/models-for-community-healthand-development/community-readiness/main

Walls, H., Baker, P., \& Parkhurst, J. (2018). Addressing trade policy as a macro-structural determinant of health: The role of institutions and ideas. Global Social Policy, 18(1), 94-101. https://doi.org/10. 1177/1468018117748700

Warin, M. (2015). Material Feminism, Obesity Science and the Limits of Discursive Critique. Body and Society, 21(4), 48-76. https:// doi.org/10.1177/1357034X14537320

Williams, O., \& Fullagar, S. (2019). Lifestyle drift and the phenomenon of 'citizen shift' in contemporary UK health policy. Sociology of Health and Illness, 41(1), 20-35. https://doi.org/10.1111/14679566.12783

Ziraba, A. K., Fotso, J. C., \& Ochako, R. (2009). Overweight and obesity in urban Africa: A problem of the rich or the poor? BMC Public Health, 9, 1-9. https://doi.org/10.1186/1471-2458-9-465

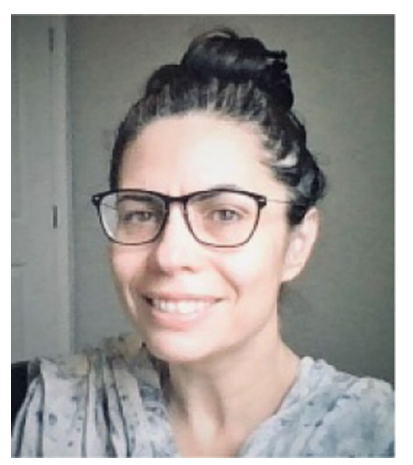

Noora-Lisa Aberman Noora-Lisa Aberman is a Senior Technical Specialist for Food Systems at the Global Alliance for Improved Nutrition. She was previously an Associate Research Fellow at the International Food Policy Research Institute in the Ghana Strategy Support Program (GSSP). She undertakes qualitative and institutional research related to food systems, nutrition, gender and agricultural. She holds a PhD in Agricultural and Natural Resource Economics from Hohenheim University and an MA in International Economic Policy from American University.

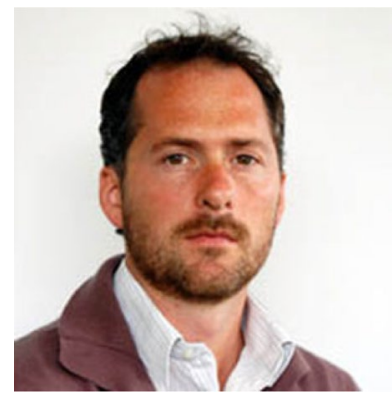

Nicholas Nisbett Nicholas Nisbettis a Senior Research Fellow at the Institute of Development Studies, UK, wherehe co-leads the institute's Health and Nutrition research cluster and teacheson development and nutrition policy. His research focuses on both applied and critical aspects of nutrition policy and interventions and he has published research on nutrition politics, equity and policy processes, community level drivers of nutrition, social accountability and theoretical approaches to food systems. He has researched, taught and consulted for a range of internationaland government organisations, including UNICEF, WFP, DFID and UNHCR. Prior to joining IDS, Nisbett spent five years working for the UK government, where he participated in intergovernmental discussions on trade and was part of the UK government's delegation to the WTO ministerial negotiations. He led teams onagricultural trade policy, agricultural policy reform and land and marine-based natural resource management, as well as a major international policy researchprogramme: the UK Government's Foresight Project on Global Food and Farming Futures. Dr. Nisbett trained originally as an anthropologist and a geographer and holds a PhD in Development Studies.

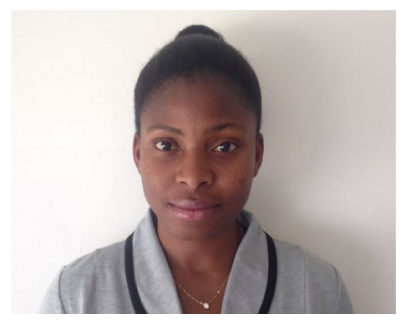

Adjoa A. Amoafo Adjoa A. Amoafois currently an independent consultant living in Accra, Ghana with her husbandand family. She holds an MSc in Nutrition and Health from Wageningen University and Research. She worked at Global Alliance for Improved Nutrition on its Social Behavioral Change

Communication (SBCC) projects. She was previously a Collaborator/ Consultant at the International Food Policy Research Institute Ghana on the Ghana Strategy Support Program (GSSP).

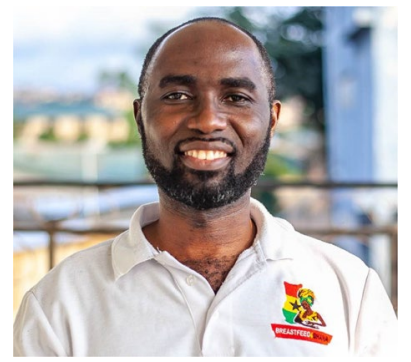

Richmond Aryeetey Richmond Aryeetey is an Associate Professor at the University of Ghana. Richmond is leading the Ghana Stories of Change in Nutrition work for Transform Nutrition West Africa and has worked in Ghana as a researcher in maternal and child health for thelast 13 years. His expertise spans Primary research skills,

formative research, and Monitoring and Evaluation, Training and Facilitation. Richmond's current research projects include studies on food environment of urban-dwelling adolescents, and exploring policy options for scaling up optimal feeding among infants and young children in Ghana. 